\title{
Prevention of Transmission of COVID-19
}

\author{
Sanskruti Tiwari \\ INTERN AT JAWAHARLAL NEHRU MEDICAL COLLEG,DATTA MEGHE INSTITUTE OF MEDICAL \\ SCIENCES,WARDHA \\ Email: sanskru2626@gmail.com
}

REVIEW ARTICLE

Conflict of Interest: None

\begin{abstract}
:
Coronavirus disease is caused by an RNA VIRUS, sars-cov-2. It has become a global pandemic. With no defined treatment modality or vaccine prevention becomes the mainstay in control of this pandemic. The spread of this disease is through contact, aerosol, fomites etc. It can be prevented with the help of social distancing, hand hygiene, respiratory hygiene and strict isolation of cases. This article deals with various interventions to stop the spread of coronavirus disease.

The outbreak of this pandemic started inHunan seafood market place, Wuhan, China. No preventive measures were taken by the Chinese authorities which led to the outbreak of this deadly disease. Human to human transmission could have been easily prevented by simple measures like quarantine, isolation etc but due to utter negligence and no proper preventive strategy this pandemic happened. The responsible thing that can be done to control the spread of this disease is prevention. Prevention is also necessary till proper treatment strategies and medicine gets approved. Research is still going on throughout the world by experts in this field to control this pandemic. Although the case fatality rate of covid 19 is still low that is less then $1.5 \%$ still it proves to be a huge disease burden in todays situation. The old and deblititated should be more careful. Prevention of this disease can only be done with the proper use of masks, hand washing and sanitization, prevention of overcrowding , proper quarantine norms, early testing and isolation of cases.
\end{abstract}

KEY WORDS-COVID-19, transmission, hand sanitization, quarantine, masks, preventive strategies, vaccine

\section{INTRODUCTION:}

Corona virus is a spherical shaped virus that contains an envelope. It is called corona virus as the term corona means crown. It appears crown like on electron microscopy. It belongs to the family, coronaviridae in the Nidoviridea order. SARS CoV-2 is a newly emerging infection and highly contagious infection of respiratory tract. Coronavirus is a spherical shaped enveloped virus it has coron like appearance due to club shaped peplomers arising from the envelop. Corona virus is a RNA single stranded virus of $100-160 \mathrm{~nm}$ in size. Corona virus targets angiotensin converting enzyme 2 (ACE-2) on respiratory mucosa.Corona virus disease was first detected in Wuhan, China in December 2019. Corona virus stain were found in patient's lower respiratory tract who presented with severe pneumonia.Corona virus infection is typically limited to mucosa cells of respiratory tract. Approximately 50\% infections are asymptomatic, severe pneumonia by Corona virus has diffuse alveolar edema resulting in hypoxia and eventually type 1 respiratory failure. The virus implicated in this pandemic is named SARS-COV-2. Other viruses from the family that have been implicated in previous outbreaks are MERS which led to outbreak of severe respiratory infection in the middle east region on the year 2009. The coronaviridae family is further divided into 4 genera- alphacoronaviridea, betacoronaviridea, gammacoronaviridae and delta coronaviridea. The current virus causing this pandemic is from the betacoronaviridea genus. The infection caused by this virus can be presented in many forms. A lot of patients are asymptomatic, few experience influenza like symptoms like fever, sore throat runny 
nose , loss of taste ,loss of smell etc. in some individuals the infection progresses to a very severe form in which is causes acute lung injury leading to atypical pneumonia. This virus has been known to infect animals, its reservoir is bats. The first known transmission was fromanimal to human. ${ }^{[1,2]}$

\section{TRANSMISSION OF SARS-COV-2}

The infection caused by SARS-COV-2 is mainly a respiratory infection though a recent study suggests that it can be spread through feco-oral route causing gastro intestinal problems. There are many environmental factors which are responsible for the spread of virus such as humidity, temperature, ventilation and sunlight(Aggravating or declining the number of coronavirus cases). cases). An imported case occurs when atraveler is infected is one area and is reported as sick in another area. Local transmission occurs whenthat traveler infects others, or there is a cluster of cases locally and the spread is easily traced.Community transmission occurs when there is no clear source of infection.Infectivity can be measured by R0 i.e reproductive number which is number of cases ,on average, thatan infected person will cause during their infectious period. Basic reproductive number is the maximum potential of a pathogen to infect people(infectious person enters community with no prior immunity). Effective reproductive number is the current vulnerability of a population based on whether people have immunity(vaccination or prior exposure). Both basic reproductive number and effectivereproductive number depends on factors such as-demographics , Environment and Virulence of the agent. $^{[3,4]}$

Modes of spread of coronavirus disease-
1) Direct
2) Indirect

Direct spread includes-
Human to human spread via droplets that can happen during sneezing, coughing, talking

Aerosol- the virus can survive in the aerosol for upto 3 hours. All aerosol generating procedures cause the spread of this pathogen. Airborne transmission is defined as the spread of an infectious agent caused by the dissemination of droplet nuclei (areosols) that remains infectious when suspended in air over long distance and time. The virus is spread mainly while coughing, talking, sneezing hence, social distancing is a major step taken to break the chain of transmission. Aerosols are infectious particle which are suspended in the air objects and people coming in contact with aerosols catch infection. Big sized aerosols remain on the ground/objects. hence, frequent handwashing for 20 seconds and sanitizer use is recommended. Depending on the size of aerosols large ones are trapped in upper respiratory tract whereas the smaller ones are inhaled and settle in alveolar region (lower respiratory tract).

- Droplet - this virus also spreads via droplet, any person inhaling these droplets can get infected.dust. Researches have shown that droplet are potent and harmful with respect to spread of the viral disease thus, studies have been concentrated on fetching more knowledge on the mechanism of droplet transmission.

\section{INDIRECT-}

- Fomites, through objects. It has been found that this virus can survive on various surfaces for variable duration. For example, it stays on plastic or stainless steel surfaces

forupto 48 hours. tract). Coronavirus can stay upto 24 hours on a cardboard, 2-3 days on plastic and stainless steel container, and upto 3 hours in aerosols which includes fog, mist and dust.

Other modes of transmission like sexual transmission, through blood, vertical transmission that is mother to child etc has 
not been seen. Research is still going on to know various other modes of transmission. FECO ORAL route of transmission has been recently noticed. This mode of transmission is not clearly understood. It is found that ACE 2 receptor found in the glandular mucosa of small bowel is what attracts the virus, the virus attaches to these receptors and replicates thereby causing gastrointestinal symptoms. ${ }^{[5,6,7]}$

\section{THE DISEASE IT CAUSES- SARS- COV-2}

The disease caused by this virus is called as corona virus disease 19 .The virus enters our body through the mucous membranes of nose and mouth. It attaches to the ACE 2 receptor present in the respiratoryepithelium. Spike proteins play a major role in binding of virus to the respiratory epithelium. This virus most commonly causes atypical pneumonia .Basically what happens in that the type II pneumocytesare damaged and their role is to maintain surface tension and so due to their damage surface tension decreases and there is alveolar collapse. Further there is accumulation of fluid and debris in the alveolus which interrupts the gaseous exchange leading to dyspnea, cough etc.. Binding of corona virus to ACE-2 is believed to beresponsible for fluid dysregulation in respiratory tract leading to edema and hypoxia. Corona virus infection is severe acute respiratory illness with fever, non productive cough and itchy sore throat. The symptoms vary from person to person. Some people present with very severe symptoms and some are asymptomatic. The severity also depends upon the immune status of a patient. Immunocompromised patients are at a higher of getting this infection. Patient with a history of hypertension , diabetes, bronchial asthma are at a higher risk .one of the most common symptom is fever and this occurs due to increase interleukin concentration in hypothalamus due to which the core body temperature increase.
The symptoms to look for early detection and testing are-

1)loss of taste

2)loss of smell

3) fever which is the most common symptom

4)diarrhea

5) dry cough

6)shortness of breath

7) tiredness

Many extrapulmonary manifestations of COVID-19 are also seen:- headache , dizziness, encephalopathy, stroke, anosmia , proteinuria , hematuria , acute kidney injury, elevated liver enzymes , nausea, vomiting, diarrhea , myocarditis, myocardial injury, arrhythmias, shock, ischemia , hyperglycemia , petechiae , erythematous rashes, urticaria, vesicles.

Complications- acute respiratory distress syndrome, ventilator associated pneumonia etc. The people exhibiting such symptoms should be promptly isolated and their samples should be sent for testing. ${ }^{[8]}$ The incubation period of this disease ranges from 2 to 14 days, people who are asymptomatic also have been found to transmit the disease. ${ }^{[9]}$ According to the new health guidelines a patient suffering from coronavirus disease are isolated for 21 days and all close contacts are quarantined and tested. The testing modality currently accepted is RT-PCR. Rapid antigen testing is also done . Antibody testing is done once the patient test negative to monitor the immune status of the patient.

\section{PREVENTION OF CORONAVIRUS DISEASE:-}

COVID-19 is a highly contagious disease which most commonly spreads via respiratory route, due to inhalation of aerosols generated by an infected person during coughing, sneezing, talking etc. This infection can also spread by touching infected surfaces and then touching one's mouth, Nose or even eyes. So it is very 
important to stops its spread because there still in no drug or vaccine available which can be considered $100 \%$ effective. The only option we are left with is to stop its transmission ${ }^{[10,11]}$

Various method of prevention of transmission of COVID-19 disease are:-

1. Hand hygiene.

2. Social distancing

3. Face mask and shield

4. Personal protective equipment

5. Sanitizer

6. Disinfectant

\section{SOCIAL DISTANCING-}

The most important mode of spread of coronavirus is via droplet or aerosol spread and the most effective method to control this is to keep a safe distance from people around. Many patients affected with this disease are asymptomatic that is they does not present with any symptoms but acts as carriers and spread the disease in the community. So the best solution is to follow social distancing norms. The government and the public needs to act coherently and follow social distancing stringently. Minimum distance that should be maintained is 1 metre. Although some also suggest 2 metres. People should avoid going to public places like train stations, flights, schools , compact office spaces and other public places where too many people come in contact with each other ${ }^{[12-}$ ${ }^{15]}$. The countries which imposed stringent lockdown during the start of this pandemic were able to contain the virus in a much manageable way as compared to those who did not. People should be encouraged to avoid public gatherings and if its mandatory they should keep a safe distance from everyone and even wear masks and avoid touching their nose and mouth. People needs to be more careful while coming in contact with people who are more at risk like elderly people, children, hypertensives, diabetics, chronic lung and heart disease patients. If social distancing is properly followed, even if an infected person coughs or sneezes and release droplets in the environment, they will not be inhaled thereby breaking the chain of transmission. Keeping all of this in mind schools, colleges and offices should be closed ${ }^{[16-18]}$.

\section{HAND HYGIENE-}

Hand hygiene plays a vital role in containing the spread of coronavirus disease. Contaminated hands on touching our face may spread infection as, face touching often results in coming in contact with mucous membrane, this results in self viral inoculation resulting in infection. WHO recommends frequent hand washing with soaps and water, in situations where proper hand washing cannot be done for example when one is outside of home, in public places etc there alcohol based rub can be used. Sanitizers used can be alcohol based and non alcohol based. Alcohol based hand sanitizers contain ethanol, isopropanol and propanol. These should be in the percentage of $60-95 \%$ volume by volume. Hydrogen peroxide can also be used which also contains alcohol ${ }^{[19-22]}$.

Alcohol free sanitizers includechloroxylenol, iodine or iodophors, triclosan ,chlorhexidine and quaternary ammonium compounds. To these hand sanitizers glycerine, coloured compounds and fragrance is added.

Mechanism of action of hand sanitizers1)alcohol based sanitizers- it denatures the protein in plasma membrane

2)chlorine compounds- oxygenates cellular proteins

3)iodine compounds- attacks proteins, nucleotides by penetrating cell membrane.

4) quaternary ammonium compoundslowers surface tension and denatures proteins ${ }^{[12,13]}$

Frequent use of hand sanitizers should be recommended. The government of India should take an initiative to spread awareness of proper steps of hand 
washing. Advertisement and radio announcements should be done on the importance of hand hygiene and proper steps of hand washing .

DISINFECTION OF SURFACESfrequent disinfection of surfaces in public places which are frequently touched by many number of people. Surfaces like door knobs, bus seats etc should be regulary disinfected. Most widely used disinfectant is sodium hypochlorite.

PERSONAL

PROTECTIVE

EQUIPMENT- personal protective equipment should be used by individuals to safeguard themselves against covid 19 infection. It includes gloves, face shield, face masks, overalls to protect clothings , goggles, foot covers etc. Along with the general population health care workers needs to protect themselves from exposure as they are continously being exposed to the patient. There is a proper way of donning and doffing the PPE, which every health care provider should practice.

Steps of donning( putting on PPE):- hand hygiene, put on gown(this should cover the entire torso including neck and upto knee, cover the arms upto wrist and tie it at the back), put on mask or respirator( tie the mask in the middle of the head, set the fixable part according to your nose and check if nose mouth and chin is appropriately covered), put on goggles or face shields and then finally put on gloves. Steps of doffing ( removing the PPE):hand hygiene while wearing gloves, remove gloves( gloves are removed in such a way that the contaminated surface should not come in contact with the bare hands, if that happens, immediately wash or sanitize with alcohol based sanitizer without moving forward in the process of doffing then discard the gloves properly), remove face shield or goggles, remove gown ( remove it in such a way that the contaminated surface should not come in contact with the body), after removing the gown fold it and put it in a bin, finally remove the mask only by touching the ties and discard it properly, the finally wash hand with soap or sanitize using alcohol based sanitiser.

Use of face masks is highly recommended by CDC in public places, face masks used by normal individuals can be surgical mask, N 95 respirator , cloth masks. Health care workers and individuals coming in direct contact with covid positive cases should wear N95 masks without valve. Universal use of masks has been shown to decrease the transmission of corona virus disease. Such an intervention is life saving in countries like India where resources are limited. ${ }^{[14]}$. It is more important for people who are symptomatic to wear a mask as it prevents droplets which may be infective to be released in the surroundings. Also people with comorbidities and high risk individuals should use proper medical masks whereas regular population can use simple masks to cover their face.

Medical masks:- these are double layered masks, loose fitting so better breathability , disposable.

Cloth mask:- These masks are made up of multiple layers of cloth, provides protection from droplet and aerosols. Easily available and can be washes and reused so economically feasible as well. Also if reusable cloth masks are used by the general population, that would decrease the tremendous amount of waste generated by disposable masks.

The Health care workers who are doing aerosols generating procedures, should all the time wear gown covering the arms and neck, face shields or eye protection, head cover and gloves to protect themselves and $\mathrm{t}$ reduce transmission.

Before wearing a mask individuals should properly wash their hands, while wearing masks full nose, mouth and chin should be covered. Masks should be kept in a clean place after use. In hospital settings proper disposal of masks should be done. ${ }^{[15]}$ 


\section{QUARANTINE AND ISOLATION IN PREVENTION OF COVID TRANSMISSION}

Quarantine- restricts the movement of people who are healthy but are potentially exposed called as contacts. It is done to monitor the symptoms of patients who have been exposed. It is for early detection. It is also done in family members of positive patients to monitor their symptoms and testing.

Isolation- it is done for cases, that is for people who have already tested positive for SARS-COV-2 infection. It is done to prevent spread of the disease and to treat the positive patient.

Quarantine should be recommended to individuals who have- 1)international travel history

2)Exposure with confirmed cases

3) Family members of positive cases

Strict isolation and quarantine should be followed. Proper monitoring of the symptoms should be done for those in quarantine.

VACCINE - research has been going on to make vaccine available for population. Various vaccine trials are going on all over the world. Even after 1 year of this pandemic, no drug of choice is available, so vaccine is our best bet to return to our normal lives. Types of vaccine being made-

1) DNA vaccine

2) Live attenuated investigational vaccine

3) Investigational mRNA vaccine

A very big challenge that the world currently faces is to make the vaccines readily available and that too it should be cost effective and safe for general public.

\section{LOCKDOWN AND SOCIAL}

DISTANCING- nationwide lockdown has been proven effective in controlling the disease burden. Social distancing norms if followed sincerely reduces transmission. All public transports are being filled only to $50 \%$ of its capacity. Social gathering of more than 50-100 people $\mathrm{s}$ being discouraged. If followed properly this mode of prevention will be very effective.Infact this is the all that we can rely on at this point of time ${ }^{[23-26]}$.

EMERGING ROLE OF VITAMIN C IN PREVENTION OF COVID 19-

Ongoing research show that people suffering from severe pneumonia and sepsis have relatively lower level of vitamin $\mathrm{c}$ in their body. Administration of vitamin $C$ in patients reduces the severity of the disease. Properties of vitamin c which helps in prevention are-1) anti oxidative

2)Anti inflammatory - reduces inflammatory mediators that cause severe covid 19 infection

3) Anti thrombotic

4) Immunomodulatory effect Advantages- 1) cost effective 2) readily available 3)excellent safety profile

Oral dose used in prophylaxis- 1-2 gram per day in healthy individuals. In people suffering from the disease huger doses are used $^{[16,17]}$

\section{CONCLUSION-}

COVID-19 disease is caused by SARCOV-2 which is a single stranded RNA virus typically causing respiratory illness common symptoms includes fever, runny nose, sore throat (mild COVID-19 infection), dry cough to atypical pneumonia and sepsis (severe COVID-19 infection). The dominant mode of transmission of COVID-19 disease is by human-to-human contact while coughing, talking, sneezing etc. hence, social distancing plays an important role in the prevention of infection. other modes of transmission of virus is by indirect contact through fomites . fomites play a major role in spread of this disease because the virus can last on many surfaces for hours. So the most important step to stop the transmission is to wear face masks which fits well and cover both nose and mouth. Along with this we need to maintain hand hygiene either by washing with soap and water or by using alcohol based sanitizer. 
People should also be encouraged not to touch their nose and mouth frequently. Also maintaining a safe distance of 1-2 metres is very effective as virus cannot enter beyond that. Along with this increasing the Rate of test would be very beneficial because this will lead to early detection and treatment of infection and would also decrease the spread of the disease.

\section{ACKNOWLEDGEMENT-}

This work is partially supported by DMIMS and furthermore information is collected from various journals

CONFLICT OF INTEREST- nil

FUNDING- DMIMS(DU), WARDHA

Ethical approval- From Institutional Ethical committee, DMIMS

\section{REFERENCES:}

[1] Novel Coronavirus 2019, Wuhan, China | CDC. 23 January 2020. Archived from the original on 20 January 2020. Retrieved 23 January 2020., 2019 Novel Coronavirus Infection (Wuhan, China): Outbreak Update. Canada.Ca. 21 January 2020.

[2] Sexton N.R., Smith E.C., Blanc H., Vignuzzi M., Peersen O.B., Denison M.R. Homology-based identification of a mutation in the coronavirusRNA-dependent RNA polymerase that confers resistance to multiple

Virol. 2016;90:7415-7428

[3] vanDoremalen N., Bushmaker T., Morris D.H., Holbrook M.G., Gamble A., Williamson B.N. Aerosol and Surface Stability of SARS-CoV-2 as Compared with SARS-CoV-1. N. Engl. J. Med. 2020

[4] Rothe C., Schunk M., Sothmann P., Bretzel G., Froeschl G., Wallrauch C. Transmission of 2019-nCoV infection from an asymptomatic contact in Germany. N. Engl. J. Med. 2020
[5] Yu P., Zhu J., Zhang Z., Han Y., Huang L. A familial cluster of infection associated with the 2019 novel coronavirus indicating potential person-to-person transmission during the incubation period. J Infect Dis. 2020

[6] Bai Y., Yao L., Wei T., Tian F., Jin D.-Y., Chen L. Presumed asymptomatic carrier transmission of COVID-19. JAMA. 2020 .

[7] Transmission of Novel Coronavirus (2019-nCoV) | CDC. 31 January 2020. Retrieved 1 February 2020.

[8] Rothe Camilla, SchunkMirjam, Sothmann Peter, Bretzel Gisela, FroeschlGuenter, Wallrauch Claudia, Zimmer Thorbjörn, Thiel Verena, Janke Christian, Guggemos Wolfgang, Seilmaier Michael, Drosten Christian, Vollmar Patrick, ZwirglmaierKatrin, Zange Sabine, Wölfel Roman, Hoelscher Michael. Transmission of 2019-nCoV Infection from an Asymptomatic Contact in Germany. New England Journal

Medicine. 2020;382(10):970-971. doi: 10.1056

[9] Zou L, Ruan F, Huang M, et al. SARS-CoV-2 viral load in upper respiratory specimens of infected patients. N Engl J Med. 2020. 10.1056/NEJMc2001737.

[10] Chang De, XuHuiwen, Rebaza Andre, Sharma Lokesh, Dela Cruz Charles S. Protecting health-care workers from subclinical coronavirus infection. The Lancet Respiratory Medicine. 2020;8(3):e13. doi: 10.1016/S2213-2600(20)30066-7

[11] Li Jie, Li Jun (Justin), XieXiaoru, CaiXiaomei, Huang Jian, TianXuemei, Zhu Hong. Game consumption and the 2019 novel coronavirus. The Lancet Infectious Diseases. 2020;20(3):275-276. doi: 10.1016/S1473-3099(20)30063-3 
[12] Mcdonnell G., Russell A.D. Antiseptics and disinfectants: Activity, action, and resistance. Clin. Microbiol. Rev. 1999;12:147-179. doi: 10.1128/CMR.12.1.147.

[13] Van Asselt A.J., TeGiffel M.C. Understanding Pathogen Behaviour. Elsevier Ltd.; Amsterdam, The Netherlands: 2005. Pathogen resistance and adaptation to disinfectants and sanitisers; pp. 484506.

[14] Centers for Disease Control and Prevention. Coronavirus Disease 2019 (COVID-19). How to Protect Yourself \&Others. Date last accessed: 3 April 2020.

[15] State Council, China Guidelines for the selection and use of different types of masks for preventing new coronavirus infection in different populations 2020 (in Chinese) Feb 5, 2020.

[16] Carr, A. and Rowe, S., 2020. The Emerging Role of Vitamin $\mathrm{C}$ in the Prevention and Treatment of COVID-19. Nutrients, 12(11), p.3286.

[17] Feyaerts, A. and Luyten, W., 2020. Vitamin $\mathrm{C}$ as prophylaxis and adjunctive medical treatment for COVID-19?. Nutrition, 79-80, p.110948.

[18] Patnaik, K.C., and D. Rajput. "Role of Antioxidant Herbs and Yoga Practices in Prevention of Infectious Diseases with Special Reference to Covid-19 Pandemic." International Journal of Research in Pharmaceutical Sciences 11, no. Special Issue 1 (2020): 317-22. https://doi.org/10.26452/ijrps.v11iSP L1.2719.

[19] Rathi, R.B., B.J. Rathi, R.S. Bhutada, D. Dasar, and R. Khatana. "Review on Role of Dhoopan in the Prevention of Airborne Infections (Covid-19)." International Journal of Research in Pharmaceutical Sciences
11, no. Special Issue 1 (2020): 24652.

https://doi.org/10.26452/ijrps.v11iSP L1.2706.

[20] Bagde, K., B. Rathi, R. Rathi, P. Badwaik, and S. Khabde. "Role of Common Kitchen Remedies in Prevention of Infectious Diseases with a Particular Perspective of COVID-19." International Journal of Research in Pharmaceutical Sciences 11, no. Special Issue 1 (2020): 137883.

https://doi.org/10.26452/ijrps.v11iSP L1.3647.

[21] Deogade, M.S. "Agnihotra (Homa)an Ayurveda Therapy in the Prevention and Control of Covid19." International Journal of Research in Pharmaceutical Sciences 11, no. Special Issue 1 (2020): 3049.

https://doi.org/10.26452/ijrps.v11iSP L1.2717

[22] Dhakite, S., and S.M. Wajpeyi. "Role of Rasayana in Prevention of COVID-19-a Review." International Journal of Research in Pharmaceutical Sciences 11, no. Special Issue 1 (2020): 716-22. https://doi.org/10.26452/ijrps.v11iSP L1.3072.

[23] Nisargandha, M.A., and S. Dadaraoparwe. "Spread of Coronavirus Disease 2019 (COVID19) during the Lockdown in the Indian Population and Preventive Measures." International Journal of Research in Pharmaceutical Sciences 11, no. Special Issue 1 (2020): 32832.

https://doi.org/10.26452/ijrps.v11iSP L1.2721.

[24] Khatod, S., A. Ikhar, P. Nikhade, and K. Khatod. "Preventive Measures for Dental Professionals during Worldwide Emergency COVID-19." International Journal of Research in Pharmaceutical Sciences 11, no. 
Special Issue 1 (2020): 150-53. https://doi.org/10.26452/ijrps.v11iSP L1.2294.

[25] Dhole, P.D., V.K. Lohe, R.P. Kadu, S.C. Mohod, M. Meshram, and G.A. Thakare. "Post COVID-19 Protocol of Treatment, Radiologic Examination and Infection Control in Dentistry." International Journal of Research in Pharmaceutical Sciences 11, no. Special Issue 1 (2020): 138489.

https://doi.org/10.26452/ijrps.v11iSP L1.3664.

[26] Late, S.V., H. Keche, V.K. Chimurkar, and V. Anjankar. "Protocol for Handling and Disposal of the Dead Bodies in Covid-19." International Journal of Current Research and Review 13, no. 1 (2021): 7-9. https://doi.org/10.31782/IJCRR.2021 .13102 . 